\title{
Value of mucin histochemistry in follow up surveillance of patients with long standing ulcerative colitis
}

\author{
JR JASS, $\dagger^{*}$ JANET ENGLAND, $\dagger$ K MILLER $\dagger$ \\ From the †Imperial Cancer Research Fund Colorectal Cancer Unit, St Mark's Hospital, and the *Medical College \\ of St Bartholomew's Hospital, London
}

SUMMARY It has been suggested that diffuse changes in epithelial mucins may help to identify a subgroup of patients with ulcerative colitis who are at increased risk of developing colorectal cancer. Colonoscopic biopsy specimens were taken from 11 colitic patients shortly before colectomies were performed, in which cancer was identified. These patients were matched to colitic patients without cancer for age, sex, and duration of disease. Sections were stained with high iron diamine and alcian blue (HID-AB), mild periodic acid Schiff, and for peanut lectin binding sugar sequences. The sections were assessed blindly and graded semiquantitatively. Most showed ulcerative colitis in remission or mild active disease. There were no differences between the study and control groups. Metaplastic foci were more common in the group who had cancer. These showed increased staining of mucus by mild periodic acid Schiff and increased binding by peanut lectin to the supranuclear (Golgi) zone. Epithelial dysplasia (detected in four of the patients with cancer showed focal intense binding by peanut lectin to cytoplasm, mucus, and glycocalyx. Although dysplasia differed histochemically from normal tissue, special techniques did not facilitate its diagnosis.

Patients with long standing extensive ulcerative colitis are at increased risk of developing colorectal cancer. ${ }^{1}$ The cumulative probability may be calculated retrospectively, but such an exercise tends to inflate the magnitude of risk. Some recent studies have indicated that the risk may be considerably lower than earlier estimates have suggested. ${ }^{2}$ Clearly, it is important to find more selective markers so that only a small number of patients need be subjected to intensive follow up surveillance. Epithelial dysplasia is one such marker, ${ }^{1}$ but there are considerable problems with regard to its sampling, sensitivity, and histopathological recognition and grading. ${ }^{4}$

It has been suggested that diffuse changes in epithelial mucins may help to identify colitic patients who are at increased risk of colorectal cancer. Filipe and colleagues recently reported an abnormal switch from goblet cell sulphomucin to sialomucin in the rectal stump biopsy specimens of six of eight patients with colitis who had previously undergone total colectomy and ileorectal anastomosis, but who subsequently went on to develop rectal cancer. ${ }^{5}$ This finding was regarded as a more sensitive indicator of cancer than epithelial dysplasia and as a useful adjunct to routine haematoxylin and eosin staining. In

Accepted for publication 11 December 1985 a prospective study of patients with long standing colitis Boland et al found that abnormal goblet cell glycoconjugates, shown by peanut lectin binding, heralded the onset of neoplastic change. ${ }^{6}$ It has also been shown, by both biochemical and histochemical means, that the sialic acid content of goblet cells is changed in patients with ulcerative colitis. ${ }^{7}$ Possibly, such a loss of side-arm $\mathrm{O}$-acetyl substituents may be especially severe in patients at increased risk of cancer, particularly as the same biochemical lesion occurs during the course of neoplastic transformation. ${ }^{89}$

This study aimed to assess the value of the mucin and lectin histochemical methods described above by comparing colonoscopic biopsy specimens from patients with ulcerative colitis complicated by cancer with those from a group of patients without cancer matched for age, sex, and duration of disease.

\section{Material and methods}

The study group included 10 patients with long standing colitis from the follow up programme at St Mark's Hospital. Colonoscopic biopsy specimens were taken from these patients shortly before they received a colectomy that led to a final diagnosis of carcinoma. An eleventh patient who did not belong to this series, but who nevertheless had received a colonoscopy and 
Table 1 Clinical details of patients in study and control groups

\begin{tabular}{|c|c|c|c|c|c|c|c|}
\hline \multicolumn{4}{|c|}{ Study group } & \multicolumn{4}{|c|}{ Control group } \\
\hline Patient & Sex & $\begin{array}{l}\text { Age when cancer } \\
\text { diagnosed }\end{array}$ & $\begin{array}{l}\text { Duration of disease } \\
\text { (years) }\end{array}$ & Patient & Sex & Age at colonoscopy & $\begin{array}{l}\text { Duration of disease } \\
\text { (years) }\end{array}$ \\
\hline $\begin{array}{r}1 \\
2 \\
3 \\
4 \\
5 \\
6 \\
7 \\
8 \\
9 \\
10 \\
11\end{array}$ & $\begin{array}{l}\mathbf{F} \\
\mathbf{M} \\
\mathbf{M} \\
\mathbf{F} \\
\mathbf{M} \\
\mathbf{M} \\
\mathbf{M} \\
\mathbf{M} \\
\mathbf{M} \\
\mathbf{F} \\
\mathbf{F}\end{array}$ & $\begin{array}{l}32 \\
55 \\
43 \\
56 \\
61 \\
31 \\
24 \\
73 \\
26 \\
54 \\
54\end{array}$ & $\begin{array}{l}16 \\
26 \\
13 \\
13 \\
14 \\
11 \\
12 \\
38 \\
13 \\
29 \\
11\end{array}$ & $\begin{array}{l}12 \\
13 \\
14 \\
15 \\
16 \\
17 \\
18 \\
19 \\
20 \\
21 \\
22\end{array}$ & $\begin{array}{l}\mathbf{F} \\
\mathbf{M} \\
\mathbf{M} \\
\mathbf{F} \\
\mathbf{M} \\
\mathbf{M} \\
\mathbf{M} \\
\mathbf{M} \\
\mathbf{M} \\
\mathbf{F} \\
\mathbf{F}\end{array}$ & $\begin{array}{l}32 \\
53 \\
40 \\
62 \\
61 \\
38 \\
32 \\
55 \\
30 \\
68 \\
43\end{array}$ & $\begin{array}{l}15 \\
25 \\
10 \\
15 \\
15 \\
10 \\
15 \\
25+ \\
10 \\
25+ \\
10\end{array}$ \\
\hline
\end{tabular}

who subsequently underwent surgery at St Mark's Hospital for colorectal cancer, was added to the study group. Eleven patients that afforded the best match for sex, age, and duration of disease were selected as controls (Table 1). The study group and control group contributed a total of 84 and 58 biopsy specimens respectively.

Five $\mu \mathrm{m}$ serial sections were cut and stained with haematoxylin and eosin for sialomucins and sulphomucins using the high iron diamine and alcian blue (HID-AB) technique, ${ }^{10}$ for $\mathrm{N}$-acetyl sialic (neuraminic) acid (NANA) using the mild periodic acid Schiff technique, ${ }^{11}$ and for peanut lectin (Sigma) binding sugar sequences using a direct immunoperoxidase technique. ${ }^{12}$ The mild periodic acid Schiff technique uses a low concentration of periodic acid ( 1 instead of the usual $44 \mathrm{mMol}$ ) and is performed at $2^{\circ} \mathrm{C}$ rather than at room temperature. It differs from periodic acid Schiff in that it fails to stain most neutral sugars, and a positive result in the colon therefore indicates the loss of $\mathrm{O}$-acetyl sialic acid and conversely, the increased expression of NANA. This technique was controlled by the use of gastric sections that contained a further inbuilt control in the form of complete intestinal metaplasia. The goblet cells of the latter secrete NANA (like normal small intestine) and are intensely positive with mild periodic acid Schiff. Unfortunately, the neutral mucus of gastric columnar cells showed moderate positivity and the pyloric glands faint positivity with the mild periodic acid Schiff technique, indicating a lack of specificity for
Table 3 Scoring system for staining techniques

\begin{tabular}{lll}
\hline Technique and interpretation & Score \\
\hline HID-AB: & 0 & \\
Sulphomucins predominate & 1 & \\
Mixed pattern & 2 & 0 \\
Sialomucins predominate & 1 & 0 \\
Mild periodic acid Schiff: & 2 & 0 \\
Negative & 0 & 0 \\
Weak diffuse or focal intense positivity & \\
Diffuse intense positivity & 1 & PNL: \\
Negative or weak staining confined to Golgi zone \\
Increased staining of Golgi zone or weak cytoplasmic \\
staining
\end{tabular}

NANA. None the less, greater specificity was achieved $\stackrel{\frac{\Omega}{\complement}}{\stackrel{2}{2}}$ by the interposition of a phenylhydrazine step $\overrightarrow{\overrightarrow{0}}$ between periodate oxidation and the Schiff effect; this 3 abolished the neutral mucus positivity. ${ }^{13}$ In the colonoscopic biopsies interposition of phenyl-? hydrazine made little or no difference to the mild periodic acid Schiff positivity, indicating that the reac-? tion was mainly due to the presence of NANA (and $\frac{5}{3}$ reduction of $\mathrm{O}$-acetyl sialic acid). Peanut lectin affinity was controlled by the use of negative (normal col- $\frac{\text { ㅇ }}{2}$ orectal goblet cells) and positive (colorectal cancer) tissue sections. Tissue controls are also essential.for $\stackrel{\circ}{=}$ the HID-AB technique and included normal colon $\frac{D}{0}$ (secretes mainly sulphomucin), normal small intestine (secretes mainly sialomucin), and stomach showing $\tilde{O}$ sulphomucin positive incomplete intestinal meta- $N$ plasia. Table 2 summarises the interpretation of the N

Table 2 Interpretation of mucin histochemical techniques

\begin{tabular}{|c|c|c|}
\hline Technique & Colour & Interpretation or specificity \\
\hline $\begin{array}{l}\text { HID-AB } \\
\text { Mild periodic acid Schiff } \\
\end{array}$ & $\begin{array}{l}\text { Brown and blue } \\
\text { Red } \\
\text { Negative }\end{array}$ & $\begin{array}{l}\text { Sulphomucins and sialomucins } \\
\text { N-acetyl-neuraminic (sialic) acid } \\
\text { Most O-acetyl neuraminic (sialic) acid } \\
\text { Neutral mucus in colon (as red colour not reduced by } \\
\text { phenylhydrazine interposition }^{13} \text { ) }\end{array}$ \\
\hline $\begin{array}{l}\text { PNL by direct immunoperoxidase technique, visualised } \\
\text { by diaminobenzidine incubation }{ }^{12}\end{array}$ & Brown & $\begin{array}{l}\text { Gal } \rightarrow^{3} \text { Gal NAc } \\
\text { Gal }^{1} \rightarrow^{3} \text { Glc NAc } \\
\text { Gal }^{1} \rightarrow^{4} \text { Glc } \text { NAc }^{22}\end{array}$ \\
\hline
\end{tabular}




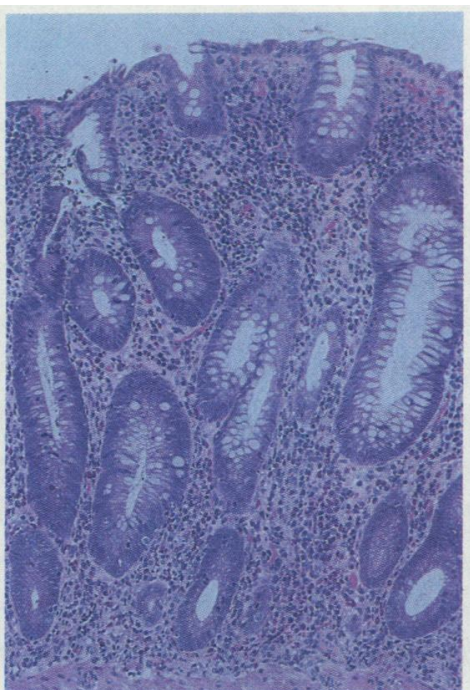

(a)

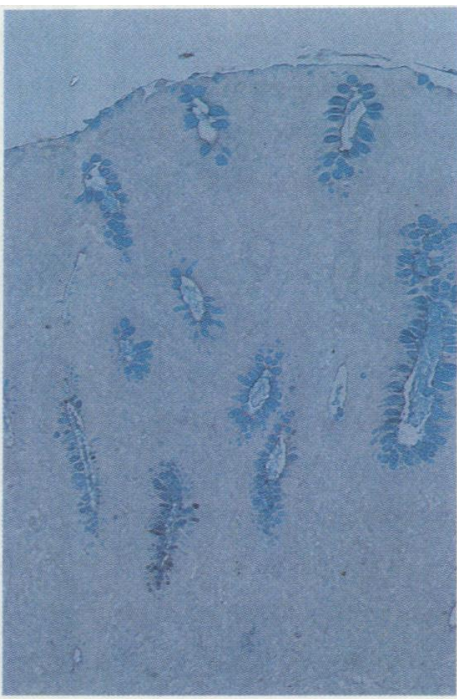

(b)

Fig. 1 Area of mild active inflammation from control group case. Sialomucin secretion predominates. (a) haematoxylin and eosin (b) HID-AB $\times 25$.

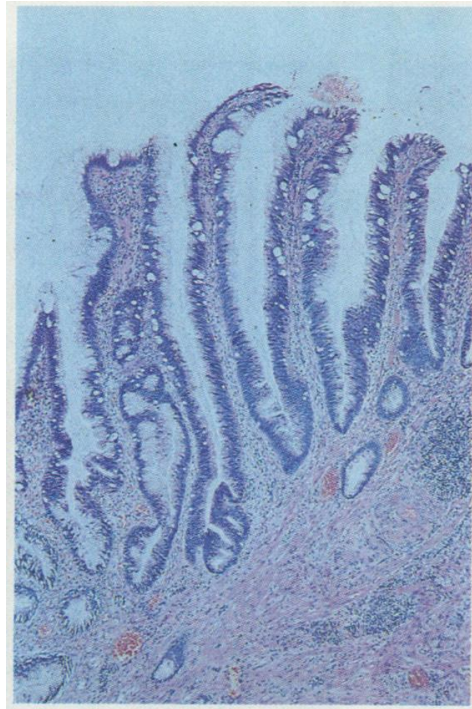

(a)

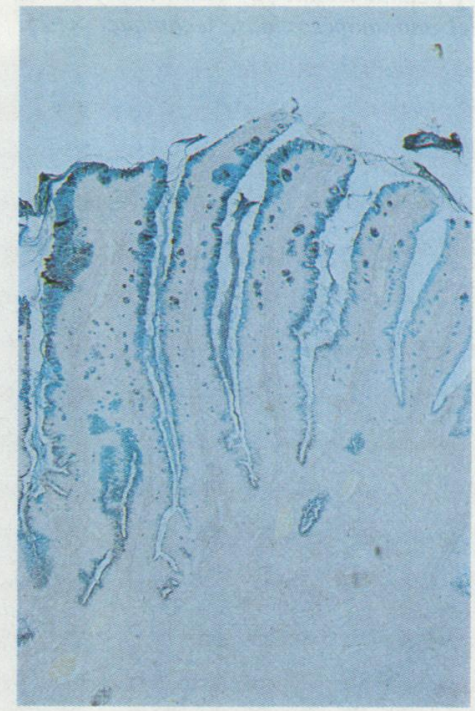

(b)

Fig. 2 Villous dysplasia from a patient in study group. Sialomucin secretion predominates. (a) haematoxylin and eosin (b) $H I D-A B \times 10$.

mucin histochemical techniques.

Sections were assessed without knowledge of the clinical history and the sections stained with haematoxylin and eosin were reviewed last. Table 3 shows how scoring was achieved. Each biopsy specimen was scored and the average score for a colonoscopic series recorded.

\section{Results}

Scoring for the HID-AB reaction was relatively straightforward. There was no difference between the study and control group (Contingency $\chi^{2}, p=N S$ ) (Table 4). Abnormal secretion of sialomucin was associated with active inflammation in four cases (Fig. 1) 


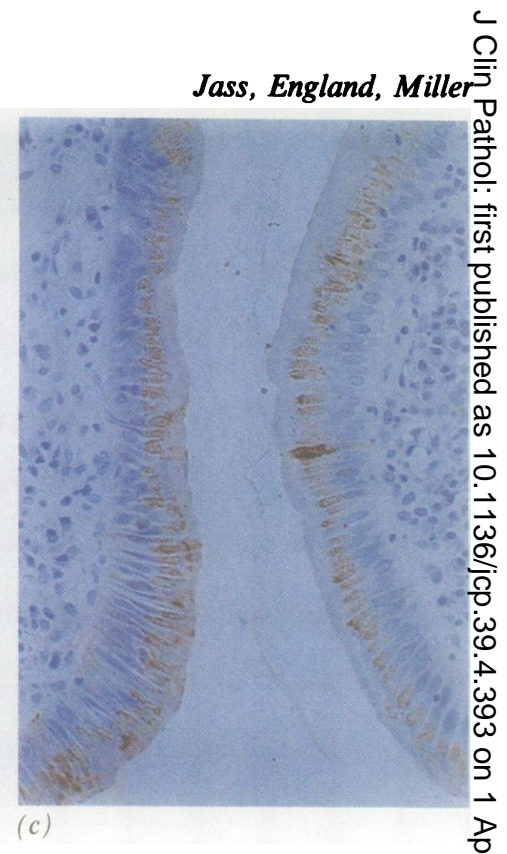

(a)

(b)

$(c)$

Fig. 3 Metaplastic change showing large numbers of columnar mucous cells and relatively few chalice shaped goblet cells. Cell apex is positive with mild periodic acid Schiff, whereas little staining is seen in Golgi zone, which shows binding by peanut lectin. (a) Haematoxylin and eosin; (b) mild periodic acid Schiff; (c) PNL incubation visualised with direct immunoperoxidase technique. $\times 25$.

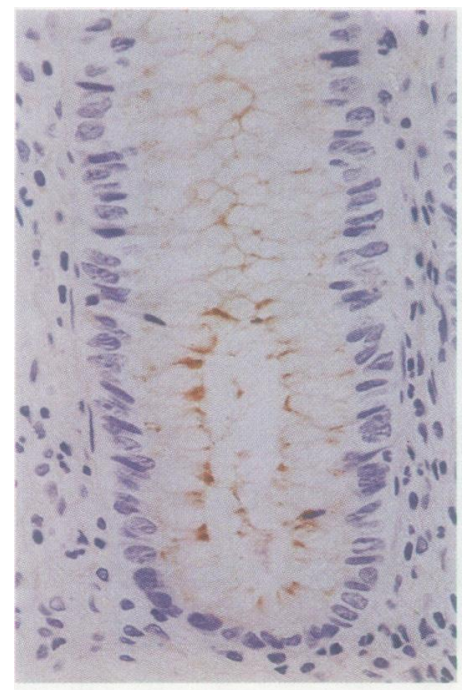

(a)

Fig. 4 Crypt base columnar cells show peanut lectin binding. Patient from control group in whom ulcerative colitis was in remission. $\times 25$.

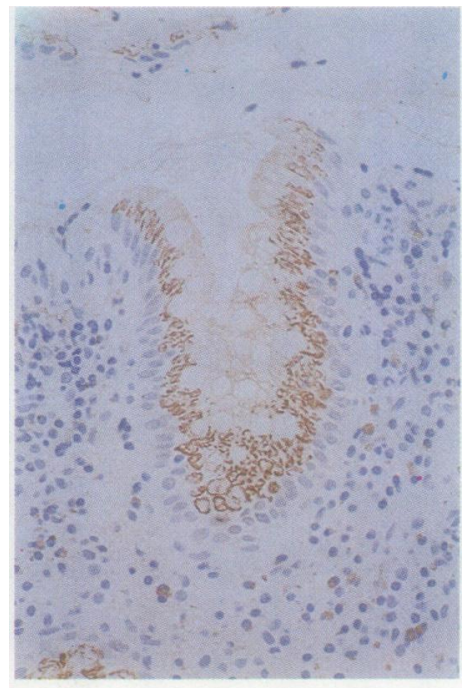

(b)

Fig. 5 Metaplastic focus showing crypt serration and PNL binding to Golgi zone of columnar cell population. $\times 25$.

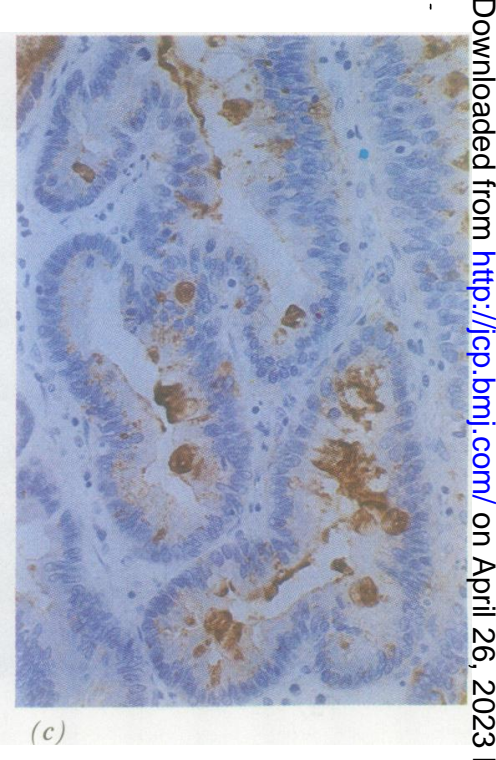

Fig. 6 Focal intense binding by $P N L$ in dysplastic epithelium. $\times 25$. and inactive disease in another four cases. Dysplastic foci secreted either sulphomucins, sialomucins, or a mixture of both (Fig. 2). The mild periodic acid Schiff technique also failed to distinguish between study and control groups (Contingency $\chi^{2}, p=N S$ ) (Table 4).
Staining ranged from a negative to an intense positive reaction entailing the entire goblet cell population? This was not related to disease activity. Dysplasia was present in four of the patients in the study group, bue again the mild periodic acid Schiff technique showed 
Table 4 Average scores (range 0-2) for mucin histochemical techniques

\begin{tabular}{|c|c|c|c|c|c|c|c|}
\hline \multicolumn{4}{|c|}{ Study group } & \multicolumn{4}{|c|}{ Control group } \\
\hline Patient & $H I D-A B^{*}$ & $\begin{array}{l}\text { Mild periodic } \\
\text { acid Schiff* }\end{array}$ & $P N L^{*} \dagger$ & Patient & $H I D-A B$ & $\begin{array}{l}\text { Mild periodic } \\
\text { acid Schiff }\end{array}$ & PNL† \\
\hline $\begin{array}{r}1 \\
2 \\
3 \\
4 \\
5 \\
6 \\
7 \\
8 \\
9 \\
10 \\
11\end{array}$ & $\begin{array}{l}0.3 \\
0.5 \\
0 \\
0 \\
0.15 \\
0.6 \\
1.0 \\
0.2 \\
0.4 \\
0.1 \\
0\end{array}$ & $\begin{array}{l}0.3 \\
0.8 \\
0.3 \\
2.0 \\
1.0 \\
2.0 \\
0.9 \\
0.65 \\
1.0 \\
0.65 \\
0.15\end{array}$ & $\begin{array}{l}0.25 \\
0.8 \\
0 \\
0 \\
0.35 \\
0.25 \\
0.15 \\
0 \\
0.65 \\
0.2 \\
0\end{array}$ & $\begin{array}{l}12 \\
13 \\
14 \\
15 \\
16 \\
17 \\
18 \\
19 \\
20 \\
21 \\
22\end{array}$ & $\begin{array}{l}2 \\
0 \\
1.5 \\
0.5 \\
1.3 \\
0.6 \\
1.5 \\
0 \\
0.3 \\
0.5 \\
0\end{array}$ & $\begin{array}{l}1.0 \\
0.8 \\
0 \\
0.3 \\
1.5 \\
2.0 \\
0.75 \\
0.5 \\
0.35 \\
2.0 \\
1.5\end{array}$ & $\begin{array}{l}1.0 \\
1.0 \\
0.4 \\
0.25 \\
0.5 \\
0.4 \\
0 \\
0 \\
0.9 \\
0 \\
0\end{array}$ \\
\hline
\end{tabular}

*Dysplastic foci excluded; tmetaplastic foci excluded

no association with this change. On the other hand, metaplastic foci that occurred in eight patients from the study group and three from the control group were always positive with mild periodic acid Schiff. These foci were characterised by crypt serration, and, more importantly, by a prominent population of columnar mucous cells (Fig. 3). Mild periodic acid Schiff positive mucus was found in the cell apex of columnar cells, but little or none could be detected in the Golgi zone. Goblet cells were also positive.

Changes in glycoconjugate as shown by PNL staining seemed to be more closely associated with an underlying morphological change. Normal mucosa showed either no staining or staining apparently confined to the Golgi zone of crypt base columnar cells (Fig. 4). Increased staining of the columnar cell Golgi zone was seen in metaplastic foci (Fig. 5). Columnar cell apical mucin droplets and goblet cells in metaplastic foci were sometimes PNL positive but this was usually a focal occurrence. Dysplastic epithelium usually showed cells that were intensely positive for PNL, but this was often a patchy or focal finding (Fig. 6). Dysplastic and metaplastic foci were graded separately; for the remaining biopsy specimens no differences were found between the control and study group (Contingency $\chi^{2}, p=N S$ ) (Table 4). It is notable, however, that one patient from the study group produced a morphologically normal biopsy specimen, in which the goblet cells were intensely positive for PNL.

\section{Discussion}

Diffuse changes in epithelial mucus may precede or accompany malignant change in patients with ulcerative colitis. Colonoscopic biopsy specimens from 11 patients with colitis and cancer were matched to 11 colitic patients without cancer for age, sex, and duration of disease. Sections were stained to show a change from sulphomucin to sialomucin, loss of O-acetyl sialomucin, and increased expression of ("cancer-associated") PNL binding sugar sequences. They were then assessed blindly. Not only were no differences found between study and control groups, but none of the methods facilitated the recognition of epithelial dysplasia. Filipe et al found abnormal sialomucins in 34 of 71 rectal biopsy specimens from colitic patients without cancer treated by colectomy and ileorectal anastomosis. ${ }^{5}$ In spite of this high false positive rate the authors strongly recommended the use of mucin stains (HID-AB) to "sharpen the assessment of dysplasia and cancer risk in patients with ulcerative colitis." 5 We would not regard the routine staining of colonoscopic biopsy specimens with HID$\mathrm{AB}$ as an essential exercise.

The mild PAS results are puzzling: they show considerable variation in staining that could not be related to an underlying morphological change (with the exception of focal metaplasia. We recently performed this technique on sections of apparently normal colorectal mucosa from patients with Crohn's disease, cancer of the left and right colon, diverticular disease, and irritable bowel syndrome. ${ }^{14}$ The findings strongly suggested the existence of goblet cell mucus heterogeneity within the general population; $8 \%$ of specimens stained with mild periodic acid Schiff showed an intense and diffuse positive reaction. Other workers using related techniques also noted goblet cell mucus heterogeneity. ${ }^{1516}$ We assume, therefore, that the five patients with colitis showing this result had a constitutional defect affecting the $\mathrm{O}$-acetylation of sialic acid. There is, however, no reason to believe that such a defect could be related to the development and progression of the disease. On the other hand, metaplastic foci showing the same change in mucus have presumably been acquired as a result of the disease. Metaplastic foci were characterised by a prominent population of columnar mucous cells and crypt serration (Fig. 3). They resembled the common metaplastic polyp. Metaplasia is well documented in ulcerative colitis, and, interestingly, the commonly acquired metaplastic (hyperplastic) polyp shows iden- 
tical mucin changes. ${ }^{17} \mathrm{~A}$ further point of similarity between metaplasia in ulcerative colitis and the common metaplastic polyp is the increased expression of PNL binding sugar sequences. ${ }^{18}$

There is disagreement regarding the normal pattern of PNL binding with colorectal epithelium. Some workers find no binding ${ }^{18}$ whereas others report a positive reaction within the goblet cell Golgi zone. ${ }^{19}$ We found a positive reaction within normal or near normal colonoscopic biopsy specimens. This seemed to be confined to the columnar cell population particularly of the lower crypts and was mainly evident in the Golgi zone. A recent study of the rat small intestinal columnar cell showed the presence of various lectin binding sugars in the Golgi zone by ultrastructural immunolocalisation. ${ }^{20}$ The secretion of glycoproteins by intestinal columnar cells has, in fact, been shown on numerous occasions, ${ }^{21}$ although this fact is not generally known. PNL is usually stated to bind specifically to the core sugar sequence $\mathrm{Gal}^{1} \rightarrow^{3} \mathrm{Gal}$ NAc, but, in fact, also binds to other sugar sequences located within the glycoprotein backbone (Table 2). ${ }^{22}$ In metaplastic foci glycoprotein synthesis by the columnar cell population increases. This is evidenced not only by increased PNL within the Golgi zone, but also by the presence of mild periodic acid Schiff positive mucus in the apical cytoplasm (Fig. 3). It seems likely that the transport of mucus from the Golgi zone (PNL positive, mild periodic acid Schiff negative) to the cell apex (PNL negative, mild periodic acid Schiff positive) is associated with the attachment of terminal sugars that include NANA.

In this study foci of metaplasia were more common in the study group (eight cases) than the control group (three cases) $\left(\chi^{2}, p>0.05\right)$. The true prevalence of the common metaplastic polyp has been established only comparatively recently by means of meticulous examination of necropsy material. These studies show that the prevalence of metaplastic polyps varies geographically in parallel with the incidence of colorectal cancer in high and low risk populations. ${ }^{23}$ Furthermore, metaplastic polyps are more common and more likely to be multiple in patients with adenomas. ${ }^{23}$ It has therefore been suggested that the metaplastic polyp could be a marker for an environmental factor implicated in the process of neoplastic transformation ${ }^{24}$; this idea could be extended to include the presence of the similar lesions in patients with ulcerative colitis. Further research in this area is required.

We thank Jill Grimsey for typing the manuscript and Professor JE Lennard-Jones, Dr CB Williams, and Dr Jean Ritchie for their clinical support.

\section{References}

${ }^{1}$ Lennard-Jones JE, Morson BC, Ritchie JK, Williams CB. Cancer surveillance in ulcerative colitis. Lancet 1983 ;ii:149-52.

${ }^{2}$ Ritchie JK, Powell-Tuck J, Lennard-Jones JE. Clinical outcome of the first ten years of ulcerative colitis and proctitis. Lancet 1978;i:1140-3.

${ }^{3}$ Mařatka Z, Nedbal J, Kociánová J, Havelka J, Kudrmann J, Hendl
J. Incidence of colorectal cancer in proctocolitis; a retrospective study of 959 cases over 40 years. Gut 1985;86:43-9.

${ }^{4}$ Riddell RH, Goldman H, Ransohoff DF, et al. Dysplasia in inflammatory bowel disease: standardized classification with provisional clinical applications. Hum Pathol 1983;14:931-68. $\frac{\vec{\sigma}}{\vec{\sigma}}$

${ }^{5}$ Ehsanullah M, Naunton-Morgan N, Filipe MI, Gazzard B. Sialomucins in the assessment of dysplasia and cancer-risk patients with ulcerative colitis treated with colectomy and ileorectal anas $-\frac{\bar{c}}{\frac{}{7}}$ tomosis. Histopathology 1985;9:223-35.

${ }^{6}$ Boland CR, Lane P, Levin B, Riddell RH, Kim YS. Abnorma尺 goblet cell glycoconjugates in rectal biopsies associated with an increased risk of neoplasia in patients with ulcerative colitis; $-\overrightarrow{-}$ early results of a prospective study. Gut 1984;25:1364-71.

${ }^{7}$ Reid PE, Culling CFA, Dunn WL, Ramey CW, Clay MG. Chem-ical and histochemical studies of normal and diseased humanw gastrointestinal tract. 1. A comparison between histologically normal colon, colonic tumours, ulcerative colitis and diverticularo disease of the colon. Histochem J 1984;16:235-51.

${ }^{8}$ Culling CFA, Reid PE, Worth AJ, Dunn WL. A new histochemica technique of use in the interpretation and diagnosis of adenocarcinomas and villous lesions in the large intestine. J Cline Pathol 1977;30:1056-62.

${ }^{9}$ Greaves P, Filipe MI, Abbas S, Ormerod MG. Sialomucins and? carcinoembryonic antigen in the evolution of colorectal cancer. Histopathology 1984;8:825-34.

${ }^{10}$ Filipe MI, Lake BD. Histochemistry in pathology. Edinburgh: Churchill Livingstone, 1983.

${ }^{11}$ Veh RW, Meessen D, Kuntz HD, May B. Histochemical demon- $\vec{\bullet}$ stration of side-chain substituted sialic acids. In: Colonic carcinogenesis. Malt RA, Williamson RCN, eds. The Hague: MTP Press Ltd, 1982: 355-65.

${ }^{12}$ Leathem A, Atkins N. Lectin bnding to formalin-fixed paraffin sections. J Clin Pathol 1983;36:747-80.

${ }^{13}$ Spicer SS. The use of various cationic reagents in histochemica施 differentiation of mycopolysaccharides. Am J Clin Pathobू 1961;5:393-407.

${ }^{14}$ Sugihara K, Jass JR. Heterogeneity of colorectal goblet,cell mucus and its relation to neoplastic disease. J Pathol 1986;148:83A.

${ }^{15}$ Lev R, Lance P, Camara P. Histochemical and morphologicaB studies of mucosa bordering rectosigmoid carcinomas: comparisons with normal, diseased and malignant colonic epi thelium. Hum Pathol 1985;16:151-61.

${ }^{16}$ Muto T, Kamiya J, Sawada T, Agawa S, Morioka Y, Utsunomiyå $\mathrm{J}$. Mucin abnormality of colonic mucosa in patients with familia? polyposis coli. A new tool for early detection of the carrier? Dis? Colon Rectum 1985;28:147-8.

${ }^{17}$ Jass JR, Filipe MI, Abbas S, Falcon CAJ, Wilson Y, Lovell D. A morphological and histochemical study of metaplastic polyps of the colorectum. Cancer 1984;53:510-5.

${ }^{18}$ Boland CR, Montgomery CK, Kim YS. A cancer-associated mucin alteration in benign colonic polyps. Gastroenterology 1982;82:664-72.

${ }^{19}$ Cooper HS. Peanut lectin-binding sites in large bowel carcinoma Lab Invest 1982;47:383-90.

${ }^{20}$ Pavelka M, Ellinger A. Localization of binding sites for Con canavalin A, Ricinus communis I and Helix pomatia lectin in the Golgi apparatus of rat small intestinal absorptive cells. $J$ Histo $-\mathrm{N}$ chem Cytochem 1985;33:905-14.

${ }^{21}$ Michaels JE. Glycoprotein containing vesicles in the surface epi thelial cells of the ascending colon of the rat. Anat Ree 1977;188:525-34.

${ }^{22}$ Picard JK, Feizi T. Peanut lectin and anti-Ii antibodies revea! structural differences among human gastrointestinal glyco proteins. Mol Immunol 1983;20:1215-20.

${ }^{23}$ Clark JC, Collan Y, Eide TJ, et al. Prevalence of polyps in an autopsy series from areas with varying incidence of large bowep cancer. Int J Cancer 1985;36:179-86.

24 Jass JR. Relation between metaplastic polyp and carcinoma of the colorectum. Lancet 1983;i:28-30.

Requests for reprints to: Dr JR Jass, ICRF Colorecta Cancer Unit, St Mark's Hospital, City Road, London EClVt 2PS, England. 